\title{
Prevalence of recurrent wheezing in infants
}

\author{
Herberto José Chong Neto, ${ }^{1}$ Nelson Augusto Rosário, ${ }^{2}$ Dirceu Solé, ${ }^{3}$ Javier Mallol ${ }^{4}$
}

\begin{abstract}
Objective: To identify the prevalence of recurrent wheezing in infants in the city of Curitiba, PR, Brazil.

Methods: A cross-sectional study carried out by means of administering questionnaires to the parents of infants aged 12 to 15 months attending health centers for immunization during the period between August 2005 and December 2006. This is a standardized and validated instrument consisting of questions on demographic characteristics, wheezing, respiratory infections and risk factors. At the time of the study the City Health Department had 107 health centers, 35 of which were selected by lots and distributed homogeneously across the municipal territory.
\end{abstract}

Results: A total of 1,364 infants (45.4\%) had episodes of wheezing during their first 12 months of life, with onset at $5.5 \pm 3.1$ months (mean \pm standard deviation), and $678(22.6 \%$ ) had had three or more episodes. In $84.6 \%$ of the wheezing children treatment was with $\beta_{2}$-agonists, with inhaled corticosteroids in $18.5 \%$, oral corticosteroids in $24.3 \%$ and leukotriene receptor antagonists were used with $5.4 \%$. The wheezing children exhibited nocturnal symptoms, intense difficulty breathing and visits to emergency services in the proportions of 58.9, 46.2 and 57.6\%, respectively; $12.7 \%$ were admitted to hospital for asthma and $10.9 \%$ had had a medical diagnosis of asthma. Nocturnal symptoms, visits to emergency, severity of symptoms, hospital admissions for asthma and medical diagnoses of asthma were all more common among those who had suffered three or more crises $(p<0.001)$.

Conclusions: There is an elevated prevalence of wheezing among the infants of Curitiba, with early onset and elevated morbidity. It is possible that these infants represent a large contingent of asthmatics.

J Pediatr (Rio J). 2007;83(4):357-362: Epidemiology, infants, wheezing, asthma, treatment.

\section{Introduction}

The epidemiology of asthma has been the motivation for several studies with the most varied ranges of age. Widely publicized, the International Study of Asthma and Allergies in Childhood (ISAAC) initiative is a method utilized to identify the prevalence of asthma and allergic diseases in a uniform manner worldwide.

The ISAAC methodology consists of the administration of a written questionnaire (WQ) and/or a video questionnaire, with the WQ being most often used as it is low cost, self-administrable and independent of trained personnel. These standardized questionnaires have been validated in several languages, including Portuguese. ${ }^{1,2}$

In phase I of ISAAC, $64 \%$ of the centers applied the written form of the questionnaire, with more than 300,000 participants and a prevalence of children with asthma during the previous 12 months varying from 1.6 to $36.8 \% .^{3}$ After an average of 7 years, phase III of this project was carried out, in 56 countries and involving approximately 500,000 schoolchildren and adolescents. At the centers that assessed

1. Doutorando em Medicina Interna, Hospital de Clínicas, Universidade Federal do Paraná (UFPR), Curitiba, PR, Brasil.

2. Professor titular, Hospital de Clínicas, UFPR, Curitiba, PR, Brasil.

3. Professor titular livre-docente, Universidade Federal de São Paulo - Escola Paulista de Medicina (UNIFESP-EPM), São Paulo, SP, Brasil.

4. Professor titular, Universidade de Santiago do Chile (USACH), Santiago, Chile.

Suggested citation: Chong Neto HJ, Rosário NA, Solé D, Mallol J. Prevalence of recurrent wheezing in infants. J Pediatr (Rio J). $2007 ; 83(4): 357-362$.

Manuscript received Feb 09 2007, accepted for publication May 162007.

doi 10.2223/JPED. 1679 
6 to 7 -year-old children, the prevalence of asthma had varied at $59 \%$, with $64 \%$ exhibiting an increased number of asthmatics, whereas, at locations that investigated children aged 13 to 14 years, $77 \%$ demonstrated variation and $51 \%$ found evidence that the prevalence of asthmatics had increased. ${ }^{4}$

In Brazil, phase I of ISAAC was initially carried out using WQ in São Paulo, Curitiba, Porto Alegre, Itabira, Recife, Salvador and Uberlândia, among other places, with the prevalence of asthma varying between 4.8 and $26.4 \%$ of children. ${ }^{5-9}$ During 2002 and 2003, phase III of ISAAC was undertaken in Brazil, with 21 participating centers in 20 cities, although nine centers only assessed adolescents. It was demonstrated that the mean prevalence rates of asthma among schoolchildren and adolescents were 24.3 and $19.0 \%$, respectively, with higher rates observed at centers closer to the equator. ${ }^{10}$

In 1995, during ISAAC phase I in Curitiba, Ferrari et al. observed that the prevalence rate of asthma symptoms among adolescents was $18.4 \%$ and, 6 years later, Riedi et al. carried out phase III of the study, observing a prevalence of asthma symptoms in adolescents of $18.7 \%$, with no increase compared with the previous evaluation. ${ }^{6,11}$

The prevalence of asthma in children under 5 years old has been little studied due to the difficulty in establishing a diagnosis of the disease in this age group and because other respiratory diseases cause wheezing and could be confused with all associated with asthma. In a one year cohort of 188 full term neonates from low income families, Mallol et al. found that $80.3 \%$ of them had had an episode of wheezing during the first year of life, $43.1 \%$ had suffered three or more crises and $44.1 \%$ had wheezed during the first 3 months. ${ }^{12}$ In the United States and England, cohort studies found evidence that the prevalence of infants who wheezed during the first year of life varied between 10 and $42 \%$, and that from 8 to $17.2 \%$ suffered more than three episodes. ${ }^{13-16}$

Despite the different methods used to investigate the prevalence rates of wheezing and asthma in infants, these are still relatively unknown and a standardized and validated instrument is being employed in order to identify these rates. The objective of this study was to identify the prevalence of recurrent wheezing in infants in Curitiba, PR, Brazil, using a standardized and validated WQ.

\section{Methods}

This study was carried out in the city of Curitiba, as part of the International Study of Wheezing in Infants (Estudio Internacional de Sibilancias en Lactantes, EISL). The EISL is a multicenter, international, cross-sectional study designed to assess prevalence, severity and other characteristics of wheezing in infants in Latin America and the Iberian peninsula during the first year of life. Furthermore, the EISL was developed to investigate the association of wheezing with other respiratory diseases, such as pneumonia, and to define possible risk factors for wheezing or pneumonia in infants during the first 12 months of their lives. This study, in common with ISAAC, employs standardized case definitions and methodology, increasing the value of comparisons between centers in different countries and facilitating international collaboration.

Before the questionnaire was applied, it was translated into Portuguese, back translated into Spanish and validated for our population. ${ }^{17}$ This instrument consists of 65 questions on demographic characteristics, wheezing, respiratory infections and risk factors. The questions referring to epidemiology are shown in Figure 1.

During the 17-month study period, the City Health Department (Secretaria Municipal de Saúde) had 107 health centers, 35 of which we selected by lots, proportionally distributed across the municipal territory. These healthcare units are administrated by eight regional administrations, each of which control a certain number of centers. Thus, if a regional administration was responsible for 20 healthcare units it corresponds to $20 / 107=18.7 \%$ of the total number. This percentage of 35 is 6.5 and was rounded up to seven healthcare units. We chose this method because if the city had simply been divided into four quadrants the resulting population distribution would not have been homogeneous, since the municipal territory is triangular in shape, with irregular demographic distribution.

During the period between August 2005 and December 2006, the parents or legal representatives of infants aged between 12 and 15 months who consecutively attended the healthcare units for routine immunization were approached and invited to take part. The study was explained to them and, if they agreed to participate, they signed an informed consent form and completed the WQ. Sixteen medical students were helping with data collection and they requested respondents to complete $95 \%$ of the questions on the instrument, avoiding leaving questions unanswered. These interviewers attended the health centers once a week on differing days. The sample was selected by convenience and totaled 3,003 infants in order to meet the study objectives.

This study was approved by the Human Research Ethics Committee at the Hospital de Clínicas, Universidade Federal do Paraná, hearing number 1024.063/2005-05, and participants' parents or legal representatives signed informed consent forms. 
1) Has your baby had wheezing in the chest or bronchitis or whistling during his/her first 12 months of life? () Yes ( ) No

2) How many episodes of wheezing in the chest (bronchitis or whistling) did your baby have during the first year?

() None () Less than 3 episodes ( ) 3 to 6 episodes () More than 6 episodes

3) At what age did your baby first have an episode of wheezing in the chest (first bronchitis)?
At months

4) Has your baby been treated with inhaled medications to relieve chest wheezing (bronchodilators) via nebulizers or inhalers (sprays)? (For example: Salbutamo ${ }^{\circledR}$, Aerolin $^{\circledR}$, Berotec $^{\circledR}$, Brycanil $^{\circledR}$ )
( ) Yes
( ) No
( ) Don't know

5) Has your baby been treated with inhaled corticosteroids (cortisones in spray form)? (For example: Symbicort ${ }^{\circledR}$, Flixotide $^{\circledR}$, Seretide ${ }^{\circledR}$, Clenil $^{\circledR}$, Becloso $^{\circledR}$, Budesonide ${ }^{\circledR}$, Busonid ${ }^{\circledR}$, Pulmicort ${ }^{\circledR}$, Beclometasone, Fluticasone, etc.)
( ) Yes
( ) No
( ) Don't know

6) Has your baby been treated with antileukotrienes (Singulair $\left.{ }^{\circledR}\right)$ ?
() Yes
( ) No
( ) Don't know

7) Has your baby been treated with oral corticosteroids (Predsim ${ }^{\circledR}$, Prelone ${ }^{\circledR}$, Decadron ${ }^{\circledR}$ )?
( ) Yes
( ) No
( ) Don't know

8) During the last 12 months, how many times have you woken up during the night because your baby was coughing or had a wheezing chest?

( ) Never

( ) Rarely (less than once a month)

( ) Sometimes (some weeks of some months)

( ) Frequently (2 or more nights per week, almost every month)

9) During the last 12 months, has the wheezing (whistling) in your baby's chest been so strong that you have had to seek emergency services (Hospital, Clinic or Health Center)?

() Yes ( ) No

10) During the last 12 months, has the wheezing (whistling) in your baby's chest been so intense that you have felt it caused great difficulty breathing (shortness of breath)?

( ) Yes ( ) No

11) Has your baby been admitted to hospital for bronchitis?

() Yes () No

12) Has a doctor ever told you your baby has asthma?

() Yes ( ) No

Figure 1 - Questions on epidemiology of recurrent wheezing

\section{Statistical analysis}

Employing the ISAAC methodology and based on prevalence rates of wheezing of 30 and $25 \%$ at two different centers, the study power is $95 \%$, with a significance level of $1 \%$ for this sample. ${ }^{1}$

Categorical variables are presented as frequency distributions. Comparisons between proportions were made using the chi-square test. The level of significance was set at $\alpha=0.05$. Statistical analysis of data was performed using Minitab 14 (Minitab, Brazil).

\section{Results}

The study included 3,003 individuals, 1,522 (50.7\%) of whom were male. Mean age at interview was $13.4 \pm 1.2$ months. Birth weight was $3.2 \pm 0.6 \mathrm{~kg}$, and current weight was $10.5 \pm 1.5 \mathrm{~kg}$. Length at birth was $48.0 \pm 3.0 \mathrm{~cm}$, and current length was $75.6 \pm 3.4 \mathrm{~cm}$. Ethnic distribution was as follows: $84.8 \%$ white, $13.9 \%$ afro-descendants, $0.6 \%$ Asian and $0.7 \%$ others.

A total of 1,364 infants (45.4\%) had suffered episodes of wheezing during their first 12 months of life, with onset of 
symptoms at $5.5 \pm 3.1$ months, with $678(22.6 \%)$ of these having had three or more episodes.

In $84.6 \%$ of the wheezing children treatment was with $\beta_{2}$-agonists, with inhaled corticosteroids in $18.5 \%$, oral corticosteroids in $24.3 \%$ and leukotriene receptor antagonists in $5.4 \%$.

Nocturnal symptoms (sometimes and frequently), intense breathing difficulties and emergency visits were reported for $58.9,46.2$ and $57.6 \%$ of the infants who wheezed, respectively; while $12.7 \%$ of these were hospitalized due to asthma and $10.9 \%$ had had a medical diagnosis of asthma.

Stratifying the wheezing infants by number of crisis as greater than or equal to three crises or less than three during the first 12 months of life, we found that nocturnal symptoms (sometimes and frequently), emergency visits, use of $\beta_{2}$-agonists, severe symptoms, hospital admissions due to asthma and medical diagnosis of asthma were all more frequent among those who had suffered three or more episodes of wheezing (Table 1 ).

\section{Discussion}

Standardized and validated WQ have been used internationally for verifying the prevalence of asthma in schoolchildren and adolescents in many different parts of the globe. ${ }^{3,4}$ In Brazil, the ISAAC initiative found evidence of an elevated prevalence of asthmatic children in the regions that were studied, putting the country in eighth position in the world and with higher rates observed at centers closer to the equator. ${ }^{3,5}$ Phases I and III of the ISAAC study were carried out at our centre and did not find evidence that the prevalence rates of children with symptoms of asthma had changed between 1995 and 2001, when prevalence rates were 18.4 and $18.7 \%$, respectively. ${ }^{6,11}$

Few studies have assessed the prevalence of wheezing and asthma in infants. In Chile, Mallol et al. demonstrated that $80.3 \%$ of infants in low income families wheezed during their first year of life and that $43.1 \%$ of these infants had suffered more than three episodes. ${ }^{12}$ In the United States and the United Kingdom, the number of children wheezing during the first year of life, according to the results of cohort studies, varied from 10 to $42 \%$, while from 8 to $17.2 \%$ suffered more than three episodes. ${ }^{13-16}$

Irrespective of the methods employed, the prevalence of wheezing and asthma in infants has not been reported,

Table 1 - Comparison between wheezing children with three or more episodes and less than three episodes of wheezing and the characteristics of their wheezing

\begin{tabular}{|c|c|c|c|}
\hline Characteristics of wheezing & $\begin{array}{l}\geq 3 \text { crises } * * \\
n=678(\%)\end{array}$ & $\begin{array}{l}<3 \text { crises } * * \\
\mathrm{n}=682(\%)\end{array}$ & $\mathbf{p}$ \\
\hline \multicolumn{4}{|l|}{ Nocturnal symptoms* } \\
\hline Never & $54(4)$ & $131(9.7)$ & \multirow{4}{*}{$<0.0001$} \\
\hline Rarely & $128(9.4)$ & $244(18)$ & \\
\hline Sometimes & $241(17.8)$ & $209(15.4)$ & \\
\hline Frequently & $254(18.8)$ & $93(6.9)$ & \\
\hline \multicolumn{4}{|l|}{ Emergency visit $^{\dagger}$} \\
\hline Yes & $470(34.7)$ & $310(22.9)$ & \multirow[t]{2}{*}{$<0.0001$} \\
\hline No & $208(15.3)$ & $368(27.1)$ & \\
\hline \multicolumn{4}{|l|}{ Treated with $\beta_{2}$-agonist ${ }^{\ddagger}$} \\
\hline Yes & $608(45.8)$ & $539(40.6)$ & \multirow[t]{2}{*}{$<0.0001$} \\
\hline No & $58(4.4)$ & $123(9.2)$ & \\
\hline \multicolumn{4}{|l|}{ Severe symptoms ${ }^{\S}$} \\
\hline Yes & $402(29.6)$ & $226(16.7)$ & \multirow[t]{2}{*}{$<0.0001$} \\
\hline No & $274(20.2)$ & $454(33.5)$ & \\
\hline \multicolumn{4}{|l|}{ Hospital admission for asthmall } \\
\hline Yes & $116(8.6)$ & $56(4.1)$ & \multirow[t]{2}{*}{$<0.0001$} \\
\hline No & $560(41.4)$ & $622(45.9)$ & \\
\hline \multicolumn{4}{|l|}{ Medical diagnosis of asthma" } \\
\hline Yes & $110(8.1)$ & $38(2.8)$ & \multirow[t]{2}{*}{$<0.0001$} \\
\hline No & $567(41.8)$ & $642(47.3)$ & \\
\hline
\end{tabular}

Number of unanswered questions: $6^{*}, 6^{+}, 6^{\ddagger}, 6^{\S}, 8^{11}, 5^{\Uparrow}, 4^{* *}$. 
whether because of the lack of standardized instruments or the difficulties involved in diagnosing asthma in this age group.

In this study we observed a prevalence rate of $45.4 \%$ infants with wheezing, with onset of crises at 5.5 months. The proportion of wheezing children who had suffered three or more crises was $22.6 \%$, higher than in developed countries, but below that found in low-income families in Chile. ${ }^{12-16}$

These differences may be related both to the level of socioeconomic and cultural development of the regions being studied and to the method that we used to determine prevalence, applying a WQ, in contrast with the other studies.

Diagnosing asthma in infants is made more difficult by other kind conditions that manifest with coughing, dyspnea and wheezing, in addition to the variety of wheezing phenotypes that have been described. ${ }^{18-20}$ In order to aid with diagnosing asthma within this age group, CastroRodriguez et al. developed a clinical score including personal and family history of atopic disease that is easy to apply and has predictive value for asthma. ${ }^{21}$

Nevertheless, according to several national and international consensus documents, the majority of asthma diagnoses are clinical, particularly in children less than five years old. These guidelines suggest a diagnosis of asthma may become easier when children have suffered three or more episodes of wheezing during the previous 12 months in conjunction with a positive answer to one of the following questions: has the child had or does the child have episodes of lack of air (dyspnea)? Has the child had or does the child have wheezing crises or recurrent episodes of wheezing? Does the child have persistent coughing, particularly at night or on waking? Is any medication given when the symptoms occur, and, if so, with what frequency ${ }^{18,19}$

Even taking into account the problems involved in making a diagnosis of asthma in children less than 5 years old and the different phenotypes of wheezing, the elevated proportion of wheezing infants that we observed, associated with the characteristics of their wheezing, it can be stated that, in our milieu, there is a high proportion of wheezing infants who are probably asthmatics.

The arbitrary cutoff of three crises proved useful to demonstrate that, in the group with three or more crises, the frequency of nighttime symptoms, more severe symptoms, need for hospital admissions and diagnosis of asthma by a doctor were all significantly greater. Recurrence of crisis more than three times, irrespective of trigger factors, severity and personal or family history of atopic disease, has already been defined as fundamental to a diagnosis of asthma; a concept reinforced by our findings. ${ }^{22}$
Analyzing the prevalence of wheezing during the previous 12 months with medical diagnosis of asthma, it is observed that there is a discrepancy with the numbers of schoolchildren and adolescents. The difficulty that doctors have in defining a recurrent wheezing disease as asthma is evident. The percentage of asthma diagnoses found, $8.1 \%$, is similar to what has been reported with older children. ${ }^{6}$

According to Rosário \& Ferrari, the low sensitivity of the question "have you ever had asthma?", associated with the absence of some questions in the ISAAC questionnaire, may have reduced the true prevalence of asthmatic children in our city, since around $70 \%$ of the probable asthmatics replied that they had never had asthma. ${ }^{6,23}$ When this instrument was validated for the study population, the question, "Has your baby had wheezing in the chest or bronchitis or whistling during his/her first 12 months of life?", confirmed by chest auscultation, exhibited better sensitivity. ${ }^{17}$ The difference being that, in ISAAC data is dependent on the memories of those completing the questionnaire, whereas, in the case of EISL, the time elapsed between events was shorter, the child was more dependent on parents and the doctor confirmed the reply by physical examination.

If we observe the elevated proportion of probable asthmatics found by our study with that found by Riedi et al., either we are overestimating our data, or we are underestimating the data produced by applying the ISAAC questionnaire in Curitiba in 1995 and $2001 .^{11}$ These figures allow us to define the $22.6 \%$ of wheezing children who suffered three or more crises as probable asthmatics, assuming that the prevalence of adolescent asthmatics in Curitiba did not vary. ${ }^{11}$

One possible limitation of this study is that the sample was a low-income population, which could result in bias, since rich and poor countries have exhibited different rates of wheezing infants in cohort studies. The question remains unanswered of whether the results would have been similar if the questionnaire had been applied to unequal social classes. ${ }^{12}$

We conclude that the prevalence of recurrent wheezing is elevated among the infants of Curitiba, with early onset and high morbidity and possibly represents a significant proportion of asthmatics.

\section{Acknowledgements}

We would like to thank the City Health Department (Secretaria Municipal de Saúde) for authorization and for making the public healthcare network available for this study.

We are also grateful to the following medical students from the Universidade Federal do Paraná for their contributions and dedication to the data collection: Bruno Guimarães Tannus, Leônidas Gustavo Tondo, Larissa Bollmann, Fernanda Valdameri Scapinello, Thaís Hissami 
Inoue, Francisco Emilio Ottmann, Arieno Cit Lorenzetti, Hugo Daniel Welter Ribeiro, Ricardo Pin, Luciana França Kalache, Renata Pimpão Rodrigues, Leonardo Dudeque Andriguetto, Emerson Rodrigues Barbosa, Kelly Cristina Vieira and Henrique Lopes and also to Universidade Positivo medical student Cristine Secco Rosário.

\section{References}

1. Asher MI, Keil U, Anderson HR, Beasley R, Crane J, Matinez F, et al. International Study of Asthma and Allergies in Childhood (ISAAC): rationale and methods. Eur Respir J. 1995;8:483-91.

2. Sole D, Vanna AT, Yamada E, Rizzo MC, Naspitz CK. International Study of Asthma and Allergies in Childhood (ISAAC) written questionnaire: validation of the asthma component among Brazilian children. J Investig Allergol Clin Immunol. 1998;8:376-82.

3. Worldwide variation in prevalence of symptoms of asthma, allergic rhinoconjunctivitis, and atopic eczema: ISAAC. The International Study of Asthma and Allergies in Childhood (ISAAC) Steering Committee. Lancet. 1998;351:1225-32.

4. Asher MI, Montefort S, Bjorksten B, Lai CK, Strachan DP, Weiland SK, et al. Worldwide time trends in the prevalence of symptoms of asthma, allergic rhinoconjunctivitis, and eczema in childhood: ISAAC Phases One and Three repeat multicountry crosssectional surveys. Lancet. 2006;368:733-43.

5. Sole D, Yamada E, Vanna AT, Costa-Carvalho BT, Naspitz CK. Prevalence of asthma and related symptoms in school-age children in São Paulo, Brazil--International Study of Asthma and Allergies in Childhood (ISAAC). J Asthma. 1999;36:205-12.

6. Ferrari FP, Rosario Filho NA, Ribas LF, Callefe LG. Prevalência de asma em escolares de Curitiba - projeto ISAAC (International Study of Asthma and Allergies in Childhood). J Pediatr (Rio J.) 1998; 74:299-305.

7. Werneck G, Ruiz S, Hart R, White M, Romieu I. Prevalence of asthma and other childhood allergies in Brazilian schoolchildren. J Asthma. 1999;36:677-90.

8. De Britto MC, Bezerra PG, Ferreira OS, Maranhão IC, Trigueiro GA. Asthma prevalence in schoolchildren in a city in north-east Brazil. Ann Trop Paediatr. 2000;20:95-100.

9. Camargos PA, Castro RM, Feldman JS. [Prevalence of symptoms related to asthma in school children of Campos Gerais, Brazil]. Rev Panam Salud Publica. 1999;6:8-15.

10. Sole D, Wandalsen GF, Camelo-Nunes IC, Naspitz CK; ISAAC Brazilian Group. Prevalence of symptoms of asthma, rhinitis, and atopic eczema among Brazilian children and adolescents identified by the International Study of Asthma and Allergies in Childhood (ISAAC) - Phase 3. J Pediatr (Rio J). 2006;82:341-6.
11. Riedi CA, Rosario NA, Ribas LF, Backes AS, Kleiniibing GF, Popija $M$, et al. Increase in prevalence of rhinoconjunctivitis but not asthma and atopic eczema in teenagers. J Investig Allergol Clin Immunol. 2005;15:183-8.

12. Mallol J, Andrade R, Auger F, Rodriguez J, Alvarado R, Figueroa L. Wheezing during the first year of life in infants from low-income population: a descriptive study. Allergol Immunopathol (Madr). 2005;33:257-63.

13. Sporik R, Holgate ST, Cogswell J. Natural history of asthma in childhood - a birth cohort study. Arch Dis Child. 1991;66:1050-3.

14. Dezateux C, Stocks J, Dundas I, Fletcher ME. Impaired airway function and wheezing in infancy: the influence of maternal smoking and a genetic predisposition to asthma. Am J Respir Crit Care Med. 1999;159:403-10.

15. Gold DR, Burge HA, Carey V, Milton DK, Platts-Mills T, Weiss ST. Predictors of repeated wheeze in the first year of life: the relative roles of cockroach, birth weight, acute lower respiratory illness, and maternal smoking. Am J Respir Crit Care Med. 1999; 160:227-36.

16. Guerra S, Lohman IC, Halonen M, Martinez FD, Wright AL. Reduced interferon gamma production and soluble CD14 levels in early life predict recurrent wheezing by 1 year of age. Am J Respir Crit Care Med. 2004;169:70-6.

17. Chong Neto HJ, Rosario N, Dela Bianca AC, Sole D, Mallol J. Validation of a questionnaire for epidemiologic studies of wheezing in infants. Pediatr Allergy Immunol. 2007; 18:86-7.

18. IV Diretrizes Brasileiras para o Manejo da Asma. J Bras Pneumol. 2006;32 Suppl 7: S447-74.

19. Global Initiative for Asthma (GINA) 2006. Global strategy for asthma management and prevention. http:// www.ginasthma.org. Acesso: 15/01/07.

20. Stein RT, Holberg CJ, Morgan WJ, Wright AL, Lombardi E, Taussig $L$, et al. Peak flow variability, methacholine responsiveness and atopy as markers for detecting different wheezing phenotypes in childhood. Thorax. 1997;52:946-52.

21. Castro-Rodriguez JA, Holberg CJ, Wright AL, Martinez FD. A clinical index to define risk of asthma in young children with recurrent wheezing. Am J Respir Crit Care Med. 2000;162(4 Pt 1):1403-6.

22. Mok J, Levison H. The wheezing infant. In: Tinkelman DG, Falliers CJ, Naspitz CK, editors. Childhood asthma: pathophysiology and treatment. New York: Marcel Dekker; 1987. p. 159-81.

23. Rosario NA, Ferrari FP. Questionnaires in asthma epidemiology. Eur Respir J. 1998;12:1000.

Correspondence:

Herberto José Chong Neto

Av. República Argentina, 2964, Portão

CEP 80610-260 - Curitiba, PR - Brazil

Tel. : +55 (41) 3016.4800

E-mail: h.chong@uol.com.br 